\title{
ambient SCIENCE

\section{New Homeopathic Formulation from Native Dry Fruits of Thar Desert, Rajasthan to Combat Mild Anaemia}

\author{
Amit KumarVyas * \\ Sparsh G Cure Homoeo Clinic; Chhabily Ghati; Goga-Gate; \\ Bikaner-334005, Rajasthan, India
}

Key words: Germplasm, Vitrification, Genetic stability.

\section{Introduction:}

Studies over the last three decades on human genomesequencing resulted in an overwhelming amount of evidence that genetic -variations play a major role in drugresponse variability (Pritchard, 2009). The same drug may have different effects on patients due to their gene-variants. Gene-variations tend to distribute throughout the world in the patterns that reflect ancient population movements (Roden et al., 2011). Very rapidly increasing population movements around the world leads social and cultural transformation, which includes land change, outmigration due to quick and easy transportation and globalized markets resulting in fast and frequent climate changes in different geographical regions of the world, accordingly, the gene-variants around the world are also

\section{Abstract}

A drug is decided on symptoms of an individual patient in homeopathy. As lifestyle and geography influence the gene expression and associated diseases, so patients may have some differences in their symptoms of a particular disease accordingly. To overcome this situation and expand the range of homeopathic formulations it will be more beneficial to include new raw material resources from untouched geographical regions of the world. Anaemia can be successfully treated with homeopathy. The presently used homeopathic remedies contain alkaloids and high oxidants polyphenolic compounds and minerals like Calcium, Iron, etc. along with other bioactive phytochemicals. Parallel to the above said gene-drug response phenomenon, seven underutilized dry fruits of Thar Desert, Rajasthan were selected, which are reported to have alkaloids, high oxidants polyphenols and minerals like calcium, Zinc, Iron etc. along with other bioactive phytochemicals like carbohydrates, proteins, energy, vitamins like C, B, and A. Aqueous-alcoholic extract ( $30 \%$ ) of some selected dry fruits of the Thar desert of Rajasthan were prepared separately and homeopathic mother tincture was prepared after mixing them in equal volumes. The medicine alongwith regular ones were given to the patients. CBC investigation reports before and after extract mixture administration were compared. Analysis of the CBC records after extract administration showed improvement in anaemic condition as indicated by mean increase of Haemoglobin Platelet count, PCV from, RBC count with no signif icant changes in other haematological indices.

changing. This large scale gene-variant distribution necessitates treatments based on genetic variation of an individual patient i.e. individualized drug treatment due to gene-variation drug response efficacy interactions, for efficient and safer treatments. That was the beauty of the wisdom of our great master Dr. C.S.F Hahnemann, "the founder father of homeopathy" that he propounded almost 200 years back the idea of choice of remedy based on body constitution on an individual, which is an individual's system and circumstances including personality behavior, fears, responses to physical environment, food preferences and so on (Oliver et al., 2016). Nowadays in allopathy medicines also, personalized-drug treatment is being practiced under the branch Pharmacogenomics.

Anaemia and specifically its most common cause iron

*Author:amitprahladvyas@yahoo.com 
deficiency is a frequent cause of morbidity in both developed and developing countries alike. Apart from this, iron-deficient anaemia also have impacts on the healthrelated quality life of patients, the greatest being lack of vitality or Fatigue (Strauss \& Auerbach, 2018). The World Health Organization (W.H.O.) says that there are about 1.62 billion people with anaemia and half of them are due to iron deficiencies. Iron-deficient anaemia is being treated in allopathy by providing iron in the bio-available form via drugs and by food supplements like red meat, fish and botanicals rich in iron and vitamin B and C, (which make iron in the bio-available form) or by both. In homeopathy, mal- nutritional anaemia is successfully treated with drugs prepared from plants like China (Chincona), Nux vomica and by combination of bio-chemic mineral salts Like Alumina and Calcareaphos etc. Whereas anaemia caused by excessive blood loss particularly in females is treated by plants like Alteris farinosa. In these plants, China is native to South America, A.farinosa is native to Europe and Nux vomica is native to hilly and wet regions of India and South East Asia. The healing properties of these homeopathic remedies are probably due to the presence of alkaloids, high oxidants and anti-inflammatory compounds poly-phenols along with other bio-active phytochemical compounds.

Anaemia is a worldwide disease and naturally, in the present-day world, the anemic patients of a particular region who have previously been migrated from different regions of the world may have differences in their genevariants. In nowadays more and more people adopting homeopathy, it will also be more signif icant and beneficial to treat iron-deficient anaemia by homeopathy's individualized drug treatment approach in this new context. About $80 \%$ of homeopathic medicines plants are originated in Europe so the remedies for iron-deficient anaemia included in materia medica are prepared from plants which are mostly of European continent origin and later on the cultivation of some of these plants might have been started in other parts of the world. Plants from countries like India and Brazil etc. have been included recently in later edition of materiamedica. Native plants have additive and synergistic effects on surrounding species including humans in comparison to exotic plant species. So it will be advantageous to include new plant botanicals from other parts of the world growing in different climatic conditions for homeopathic formulations in the context of positive effects of native plants on human health as well as effects of climatic changes on gene variant-drug response efficacy interactions.

Thar desert of Rajasthan is one such region that has under-exploited and un-exploited highly nutritious fruits and vegetables, which are also rich in iron and vitamin B \& C along with, alkaloids,poly-phenolic compounds, proteins, carbohydrates, fats, minerals, and trace elements. Traditionally these are used as food and food supplements as well as medicines and nutraceuticals to treat various diseases including inflammation and anaemia also. We selected 7 of these dry fruits viz. unripe fruits of Prosopis cineraria ,Capparis decidua, Cymbopogan tetragnobolis, Leptadenia pyrotechnica, ripe fruits of Ziziphus nummularia, seeds of Citrulus lanatus and Cucumis colossus (which contains alkaloids and polyphenols along with other bioactive phytochemicals and are rich in minerals like calcium, iron, Phosphorous and vitamin B \& C) on the basis of their nutritional qualities and phytochemical analysis and with no known health hazards, (if used in smaller quantities in regular manner), to prepare a new homeopathic formulation by mixing their aqueousalcoholic extracts (30\%) to treat iron def icient anaemia due to malnutrition. To best of our knowledge, at present, there is no such formulation prepared from these Thar Desert dry fruits to treat anaemia in homeopathy. Preliminary results of the very robust primary nature clinical experiment conducted in a local homeopathic clinic showed increasing trends in hematological parameters like hemoglobin, RBC count, Platelets numbers, WBC numbers, and PCV within admissible safer upper limits and no significant changes in $\mathrm{MCV}, \mathrm{MCH}, \mathrm{MCHC}$, and DLC. Long term and more detailed and exhaustive studies are further required.

\section{Methodology:}

Unripe dry fruits of Prosopis cineraria, Capparis decidua, Cymbopogan tetragnobolis, Leptadenia pyrotechnica, ripe fruits of Ziziphus nummularia and seeds of Citrullus lanatus and Cucumis colossus were purchased from the local market in Bikaner, Rajasthan. The data for nutritional and phytochemical parameters of these were taken from the literature (Jadhav et al., 2019). These were separately ground in a domestic grinder, 10o-gram powder of each was taken separately and kept insufficient volume of aqueousalcoholic (30\%) mixture for 15 days and intermittently pounded to prepare homeopathic mother tincture. Equal volumes of these 7 mother tinctures were mixed and pounded to prepare new homeopathic formulation. Further, 10 drops thrice a day was given to 10 outdoor patients of a local homeopathic clinic for 28 days along with their regular homeopathic remedies to test the effect of this formulation on their hematological parameters. Written consent from the patients was obtained. The $\mathrm{CBC}$ reports of the patients before and after administration were collected and compared.

\section{Results and Discussion:}

The therapeutic uses of dry fruits from 7 selected plant; Ber (Ziziphus mummularia), Cluster bean (Cymposis tetragonolobus), Kachari (Cucumis callosus), Kair (Capparis decidua), Khimp (Leptadenia pyrotechnica), Khejari pods (Prosopis cineraria) Mateera (Citrullus lanatus) and their nutritional and phytochemical attributes are already reported in various literature, (Jadav et al., 2019; Rathore, 2009). These plants are rich sources of proteins, 
Table-1: CBC Comparisons before and after treatments (doses)

\begin{tabular}{llllllllllllllllllllll}
\hline $\begin{array}{l}\text { Para } \\
\text { meter }\end{array}$ & B/F & A/F & B/F & A/F & B/F & A/F & B/F & A/F & B/F & A/F & B/F & A/F & B/F & A/F & B/F & A/F & B/F & A/F & B/F & A/F \\
\hline HB & 9.6 & 11.3 & 10.5 & 11.0 & 12.2 & 11.1 & 13.8 & 14.4 & 11.3 & 12.6 & 10.0 & 10.7 & 13.0 & 13.6 & 11.2 & 11.0 & 13.4 & 14.4 & 11.8 & 11.8 \\
WBC & 51 & 86 & 88 & 80 & 62 & 54 & 78 & 75 & 72 & 77 & 81 & 91 & 78 & 98 & 95 & 89 & 30 & 66 & 81 & 92 \\
PLT & 225 & 491 & 240 & 300 & 298 & 430 & 210 & 262 & 390 & 422 & 192 & 206 & 393 & 304 & 397 & 435 & 144 & 216 & 293 & 345 \\
TRBC & 2.96 & 3.54 & 3.0 & 3.5 & 4.14 & 4.30 & 5.0 & 5.41 & 4.51 & 4.91 & 3.97 & 4.03 & 4.58 & 4.92 & 4.18 & 4.06 & 5.06 & 5.29 & 4.58 & 4.73 \\
PCV & 28.5 & 34.7 & 30.0 & 36.0 & 32.9 & 35.1 & 43.6 & 46.4 & 36.8 & 40.5 & 32.0 & 34.5 & 41.0 & 40.8 & 38.0 & 34.7 & 43.8 & 45.9 & 38.5 & 39.6 \\
MCV & 96.3 & 92.0 & 85.0 & 88.0 & 79.0 & 82.0 & 85.2 & 86.0 & 82.0 & 82.0 & 84.9 & 85.7 & 89.5 & 83.0 & 91.0 & 85.0 & 87.0 & 87.0 & 83.5 & 83.8 \\
MCH & 32.4 & 31.9 & 26.0 & 25.0 & 65.9 & 25.8 & 27.0 & 26.6 & 25.2 & 25.6 & 26.7 & 26.5 & 28.4 & 27.6 & 26.9 & 27.2 & 26.6 & 27.2 & 25.7 & 24.9 \\
MCHC & 33.7 & 32.6 & 29.0 & 30.0 & 83.0 & 31.6 & 31.7 & 31.0 & 30.9 & 33.1 & 31.9 & 31.0 & 31.7 & 33.3 & 29.5 & 31.8 & 30.6 & 31.5 & 30.8 & 29.7 \\
RDW & -- & -- & -- & -- & 13.7 & 13.4 & 13.7 & 13.9 & 18.9 & 14.2 & -- & -- & 44.7 & -- & -- & 14.0 & 14.1 & 14.0 & -- & -- \\
MPV & -- & -- & -- & -- & 6.0 & 6.2 & 12.5 & 7.3 & 5.8 & 6.1 & -- & -- & 9.8 & -- & -- & 6.5 & 8.1 & 7.4 & -- & -- \\
PDW & -- & -- & -- & -- & 12.6 & 13.6 & 15.2 & 14.5 & 12.9 & 12.7 & -- & -- & 10.5 & -- & -- & 14.0 & 16.4 & 15.4 & -- & -- & - \\
PCT & -- & -- & -- & -- & .178 & -- & -- & .192 & .225 & - & -- & -- & .39 & -- & -- & -- & .116 & .160 & -- & -- \\
\hline
\end{tabular}

carbohydrates, fats as well as iron and vitamin $\mathrm{B}$ and $\mathrm{C}$ along with other beneficial components. The range of iron content is highest $(6.09 \mathrm{mg} / 100 \mathrm{gm})$ in Citrullus lanatus to lowest $(0.18 \mathrm{mg} / 100 \mathrm{gm})$ in Cucumis colossus and vitamin C highest (85 mg/10ogm) in Ziziphusnu mmularia and lowest (6mg/1oogra) in Citrullus lanatus. The iron and vitamin C contents of these dry fruits are very significant and high enough from most of the commonly used fruits and nutritional supplements used for the treatment and management of iron-deficient anaemia. Therefore the mixtures of the processed extract powder of these plants may be used as food supplements for iron deficiencies in place of similar allopathic food supplements.

The statistical data analyses of the experimental data are shown Table-1 to 4 . This data indicated to get a paired comparison of the patient has been done before and after.

* indicates that the differences were significant at level of $5 \%$ or $1 \%$. and NS indicates that the values before and after were not significant or different from each other. correlation is the association between the values before and after and they have also been indicated.

Table-2: DLC Comparisons before and after treatments (doses)

\begin{tabular}{|c|c|c|c|c|c|c|c|c|c|c|c|}
\hline NP & & LC & & EP & & $\mathrm{M}$ & & BP & & B-C & \\
\hline B & A & B & A & B & A & B & A & B & A & B & A \\
\hline 55 & 60 & 40 & 35 & 03 & 03 & 02 & 02 & oo & oo & -- & -- \\
\hline 59 & 57 & 36 & 37 & 03 & 03 & 02 & 03 & oo & oo & oo & oo \\
\hline 51 & 54 & 44 & 36 & 03 & o6 & 02 & 04 & oo & oo & oo & oo \\
\hline 57 & 60 & 38 & 35 & 04 & 03 & 01 & 02 & oo & oo & oo & oo \\
\hline 70 & 65 & 26 & 30 & 03 & 03 & 01 & 02 & oo & oo & oo & oo \\
\hline 63 & 66 & 32 & 30 & 03 & 02 & 02 & 02 & oo & oo & oo & oo \\
\hline 45 & 53 & 44 & 41 & 02 & 03 & 09 & 03 & oo & oo & oo & oo \\
\hline 67 & 63 & 28 & 30 & 02 & $\mathrm{O} 4$ & 03 & 03 & oo & oo & oo & oo \\
\hline 38 & 34 & 46 & 51 & 02 & 01 & 03 & 04 & oo & oo & oo & oo \\
\hline 55 & $5^{8}$ & 40 & 38 & 03 & 02 & 02 & 02 & oo & oo & oo & oo \\
\hline
\end{tabular}

NP- Neutrophills, LC- Lymphocytes, EP- Eosinophils, MCmonocytes, BP-Basophils, B-c-Band cells
Table -3:- CBC Comparison In Statistical Mode

\begin{tabular}{|c|c|c|c|c|c|}
\hline & Period & Mean & SEM & T value & Corr. coeff. \\
\hline \multirow[t]{2}{*}{$\mathrm{Hb}$} & Before & 11.68 & $0.45^{2}$ & -2.028 & $0.848^{* *}$ \\
\hline & After & 12.19 & 0.461 & & \\
\hline \multirow[t]{3}{*}{ WBC } & Before & 71.60 & 6.076 & -1.748 & 0.527 NS \\
\hline & After & 80.80 & 4.224 & & \\
\hline & After & 3.00 & 0.422 & & \\
\hline \multirow[t]{2}{*}{ PLT } & Before & 0.03 & 28.826 & -2.203 & 0.554 NS \\
\hline & After & 0.03 & 31.442 & & \\
\hline \multirow[t]{2}{*}{ TRBC } & Before & 4.20 & 0.231 & -3.992 & $0.956^{* *}$ \\
\hline & After & 4.47 & 0.216 & & \\
\hline \multirow[t]{2}{*}{ PCV } & Before & 36.51 & 1.731 & -2.615 & $0.860^{* *}$ \\
\hline & After & 38.82 & 1.450 & & \\
\hline \multirow[t]{2}{*}{ MCV } & Before & 86.34 & 1.554 & 0.812 & $0.714^{*}$ \\
\hline & After & 85.45 & 0.971 & & \\
\hline \multirow[t]{2}{*}{ MCH } & Before & 31.08 & 3.922 & 1.066 & -0.023 NS \\
\hline & After & 26.83 & 0.636 & & \\
\hline \multirow[t]{2}{*}{ МСНC } & Before & 36.28 & 5.208 & 0.907 & 0.046 NS \\
\hline & After & 31.56 & 0.381 & & \\
\hline \multirow[t]{2}{*}{ RDW } & Before & 10.51 & 4.503 & 0.739 & 0.116 NS \\
\hline & After & 6.95 & 2.318 & & \\
\hline \multirow[t]{2}{*}{ MPV } & Before & 4.22 & 1.52555 & 0.656 & 0.534 NS \\
\hline & After & $3 \cdot 35$ & 1.124 & & \\
\hline \multirow[t]{2}{*}{ PDW } & Before & 6.76 & 2.306 & -0.141 & $0.684^{*}$ \\
\hline & After & 7.02 & 2.350 & & \\
\hline \multirow[t]{2}{*}{ PCT } & Before & 0.09 & 0.043 & 1.074 & $-0.148 N S$ \\
\hline & After & 0.04 & 0.024 & & \\
\hline
\end{tabular}

Table-4: DLC comparison in Statistical mode

\begin{tabular}{llllll}
\hline \multirow{2}{*}{ Neutrophil } & Period & Mean & SEM & T value & Corr. coeff. \\
& Before & 56.0 & 3.07 & -0.715 & $0.892^{* *}$ \\
Lymphocyte & Befter & 57.0 & 2.89 & & \\
& After & 37.4 & 2.17 & 0.855 & $0.814^{* *}$ \\
Eiosinophil & Before & 2.8 & 2.01 & & \\
& After & 3.0 & 0.20 & -0.452 & 0.717 \\
Monocyte & Before & 2.7 & 0.73 & 0.000 & 0.403 \\
& After & 2.7 & 0.26 & & \\
Basophil & Before & $0.0^{\mathrm{a}}$ & 0.00 & - & $\mathrm{NS}$ \\
& After & $0 . \mathrm{o}^{\mathrm{a}}$ & 0.00 & & \\
\multirow{2}{*}{ Band cells } & Before & $0 . \mathrm{o}^{\mathrm{a}}$ & 0.00 & - & $\mathrm{N}$ \\
& After & $0 . \mathrm{o}^{\mathrm{a}}$ & 0.00 & & \\
\hline
\end{tabular}

${ }^{*} \mathrm{p}<0.05,{ }^{* *} \mathrm{p}<0.01$, NS Non Significant 
As alkaloids and poly-phenolic substances obtained from the selected native Thar desert-dry fruits are soluble in polar solvents like water and alcohol and therefore, the homeopathically prepared mother tinctures of these dry fruits will contain anti-inflammatory alkaloids and polyphenolics compounds along with other bioactive phytochemicals of these fruits. Alleviation of the inflammatory conditions in the body may increase the ferrous iron absorption capacity of the erythrocytes and thus will help to improve the mal nutritional induced iron deficiency anaemia. Comparison of $\mathrm{CBC}$ reports before and after 28 days of formulation administration showed improvement in iron-deficient anaemia as indicated by mean increase in hemoglobin content from 11.68 to 12.19 $\mathrm{g} / \mathrm{dl}$, WBC count from 7,16,ooo to 8,08, ooo, platelets count from 3, o8, 200 to 3, 41,400 , PCV from $37.51 \%$ to $38.42 \%$, RBC count from 4, 19, 800 to 4,46,90o with no noticeable changes in other hematological parameters like $\mathrm{MCH}$, $\mathrm{MCHC}, \mathrm{MCV}$, and DLC. In comparison to the reported period of 30-45 days for observing positive effects of hematological parameters by commonly used homeopathic remedies, the increasing trend of hematological parameters within normal range values was observed only after 28 days in the case of desert plants derived homeopathic mother tincture. It shows that homeopathically prepared aqueous-alcoholic mixture of native dry fruits of the Thar desert have a more positive effect at least in terms of the shorter time period in comparison to the common homeopathic remedies for iron deficiency anaemia due to malnutrition in this region. This very preliminary and robust study and further long term and detailed studies are required to come in some rigid conclusions.

\section{References:}

Jadhav, S.S., Tiwari, P., Lata, K., Tyagi, E., Shete, P. Rakh, J.A., Pandey, R. \& Jadhav, A.B. (2019): Iron Deficiency Anaemia \& Ferrum Phosphoricum: A Systematic Review. Int. J. Res. Rev., 6(2):83-91.

Oliver, I., Dorrough, J., Doherty, H. \& Andrew, N.R. (2016): Additive and synergistic effects of land cover, land use and climate on insect biodiversity. Landsc. Ecol., 31(10):2415-2431.

Pritchard, J. K. (2009): Geography and History Shape Genetic Differences in Humans. Online Pub. By: Howard Hughes Medical Institute.

Rathore, M. (2009): Nutrient content of important fruit trees from arid zone of Rajasthan. J. Horticul. Forest., 1(7):103-108.

Roden, D.M., Wilke, R.A., Kroemer, H.K. \& Stein, C.M. (2011): Pharmacogenomics: the genetics of variable drug responses. Circulation. 123(15):1661-1670.

Strauss, W.E. \& Auerbach, M. (2018): Health-related quality of life in patients with iron deficiency anemia: impact of treatment with intravenous iron. Patient Relat Outcome Meas., 9:285298. 